\title{
Heart Rate and Oxygen Saturation Change Patterns During 6-min Walk Test in Subjects With Chronic Thromboembolic Pulmonary Hypertension
}

\author{
Takeshi Inagaki PT MSc, Jiro Terada MD PhD, Misuzu Yahaba MD PhD, \\ Naoko Kawata MD PhD, Takayuki Jujo MD PhD, Kengo Nagashima PhD, \\ Seiichiro Sakao MD PhD, Nobuhiro Tanabe MD PhD, and Koichiro Tatsumi MD PhD
}

\begin{abstract}
BACKGROUND: The 6-min walk test (6MWT) is commonly performed to assess functional status in patients with chronic thromboembolic pulmonary hypertension. However, changes in heart rate and oxygen saturation $\left(\mathrm{S}_{\mathrm{pO}_{2}}\right)$ patterns during 6MWT in patients with chronic thromboembolic pulmonary hypertension remain unclear. METHODS: Thirty-one subjects with chronic thromboembolic pulmonary hypertension were retrospectively evaluated to examine the relationships between the change in heart rate ( $\Delta$ heart rate), heart rate acceleration time, slope of heart rate acceleration, heart rate recovery during the first minute after 6MWT (HRR1), change in $\mathrm{S}_{\mathrm{pO}_{2}}$ $\left(\Delta \mathrm{S}_{\mathrm{pO}_{2}}\right), \mathrm{S}_{\mathrm{pO}_{2}}$ reduction time, and $\mathrm{S}_{\mathrm{pO}_{2}}$ recovery time during $6 \mathrm{MWT}$, and the severity of pulmonary hemodynamics assessed by right heart catheterization and echocardiography. RESULTS: Subjects with severe chronic thromboembolic pulmonary hypertension had significantly longer heart rate acceleration time $(144.9 \pm 63.9 \mathrm{~s}$ vs $96.0 \pm 42.5 \mathrm{~s}, P=.033)$, lower $\Delta$ heart rate $(47.4 \pm 16.9 \mathrm{vs}$ $61.8 \pm 13.6$ beats, $P=.02)$, and lower HRR1 $(13.3 \pm 9.0$ beats vs $27.1 \pm 9.2$ beats, $P<.001)$ compared to subjects with mild chronic thromboembolic pulmonary hypertension. Subjects with severe chronic thromboembolic pulmonary hypertension also had significantly longer $\mathrm{S}_{\mathrm{pO}_{2}}$ reduction time $(178.3 \pm 70.3 \mathrm{~s}$ vs $134.3 \pm 58.4 \mathrm{~s}, P=.03)$ and $S_{\mathrm{po}_{2}}$ recovery time $(107.6 \pm 35.3 \mathrm{~s}$ vs $69.8 \pm 32.7 \mathrm{~s}, P=.004)$ than did subjects with mild chronic thromboembolic pulmonary hypertension. Multivariate linear regression analysis showed only mean pulmonary arterial pressure independently was associated with heart rate acceleration time and slope of heart rate acceleration. CONCLUSIONS: Heart rate and $\mathrm{S}_{\mathrm{pO}_{2}}$ change patterns during 6MWT are predominantly associated with pulmonary hemodynamics in subjects with chronic thromboembolic pulmonary hypertension. Evaluating heart rate and $\mathrm{S}_{\mathrm{pO}_{2}}$ change patterns during 6MWT may serve as a safe and convenient way to follow the change in pulmonary hemodynamics. Key words: six-minute walk test; chronic thromboembolic pulmonary hypertension; heart rate; oxygen saturation; pulmonary hemodynamics; disease severity. [Respir Care 2018;63(5):573-583. (C) 2018 Daedalus Enterprises]
\end{abstract}

\section{Introduction}

Chronic thromboembolic pulmonary hypertension is caused by unresolved thromboembolism of the pulmonary arteries, leading to right heart failure and death. ${ }^{1-3}$ Impair-

Drs Terada, Yahaba, Kawata, Jujo, Sakao, Tanabe, and Tatsumi, as well as Mr Inagaki, are affiliated with the Department of Respirology, Graduate School of Medicine, Chiba University, Chiba, Japan. Mr Inagaki is also affiliated with the Division of Rehabilitation, Chiba University Hospital, Chiba, Japan. Drs Jujo and Tanabe are also af- ment of exercise capacity due to limited pulmonary circulation, which induces right ventricular overload, restricted stroke volume, ventilation-perfusion mismatch, and exercise-induced hypoxemia, is an important feature of chronic thromboembolic pulmonary hypertension. In clinical set-

filiated with the Department of Advanced Medicine in Pulmonary Hypertension, Graduate School of Medicine, Chiba University, Chiba, Japan. Dr Nagashima is affiliated with the Department of Global Clinical Research, Graduate School of Medicine, Chiba University, Chiba, Japan. 
tings, the 6-min walk test (6MWT) is routinely performed to assess the functional status of chronic thromboembolic pulmonary hypertension. ${ }^{4}$ Among the variables included in the 6MWT, the 6-min walk distance (6MWD) is a primary outcome that reflects hemodynamic severity, functional capacity, and survival in patients with chronic thromboembolic pulmonary hypertension, especially in clinical trials evaluating the response to medical treatments. ${ }^{5-7} \mathrm{How}-$ ever, the practical utility of other parameters such as heartrate response or oxygen desaturation-resaturation patterns in each disease state of chronic thromboembolic pulmonary hypertension remains unclear.

Variables derived from the 6MWT (other than the 6MWD) have been investigated in subjects with chronic respiratory diseases. Abnormal heart rate recovery at $1 \mathrm{~min}$ (HRR1), which is the reduction in heart rate at $1 \mathrm{~min}$ after exercise, is known to be a strong predictor of pulmonary hypertension in idiopathic pulmonary fibrosis ${ }^{8}$ and clinical worsening in pulmonary arterial hypertension (PAH) $.^{9} \mathrm{Im}-$ pairment in the heart-rate response during the 6MWT, also known as a chronotropic response, has been considered to predict 6MWD in idiopathic and nonidiopathic PAH. ${ }^{10}$ Furthermore, oxygen saturation $\left(\mathrm{S}_{\mathrm{pO}_{2}}\right)$ change patterns during the 6MWT in subjects with COPD were reported to predict peak exercise and air flow limitations. ${ }^{11}$ Regarding subjects with chronic thromboembolic pulmonary hypertension, one recent report described that exercise-induced desaturation during the 6MWT was observed in operable chronic thromboembolic pulmonary hypertension before pulmonary endarterectomy (PEA). And that heart rate during the 6MWT reserve [(peak heart rate - resting heart rate $) /(220$ - age - resting heart-rate response)] was associated with pulmonary vascular resistance 1 y post PEA. ${ }^{12}$ Thus, additional parameters of the 6MWT, such as heart rate and $\mathrm{S}_{\mathrm{pO}_{2}}$ change patterns, might have the potential to reveal more precise physiological states of chronic thromboembolic pulmonary hypertension. However, the confounding factors of chronic thromboembolic pulmonary

Drs Tanabe, Sakao, Terada, and Tatsumi have disclosed relationship with Ministry of Education, Culture, Sports, Science and Technology of Japan, and with The Intractable Respiratory Diseases and Pulmonary Hypertension Research Group, the Ministry of Health, Labor and Welfare, the Pulmonary Hypertension Research Group from the Japan Agency for Medical Research and Development, AMED. Dr Tanabe has received honoraria for lectures from Actelion Pharmaceuticals and Pfizer. Dr Tatsumi has received honoraria for lectures from Actelion. Drs Tanabe and Jujo belong to the Endowed Department, sponsored by Actelion. The other authors have disclosed no conflicts of interest.

Correspondence: Jiro Terada MD PhD, Department of Respirology, Graduate School of Medicine, Chiba University, 1-8-1 Inohana Chuo-ku, Chiba 260-8670, Japan. E-mail: jirotera@ chiba-u.jp.

DOI: $10.4187 /$ respcare. 05788

\section{QUICK LOOK}

\section{Current knowledge}

The 6-min walk test (6MWT) is routinely performed to assess the functional status of patients with chronic thromboembolic pulmonary hypertension. The 6-min walk distance (6MWD) is a primary outcome that reflects hemodynamic severity, functional capacity, and survival in patients with chronic thromboembolic pulmonary hypertension.

\section{What this paper contributes to our knowledge}

Heart rate acceleration and recovery time were slower and the slope of heart rate acceleration was less steep during 6MWT in subjects with severe chronic thromboembolic pulmonary hypertension than in those with mild chronic thromboembolic pulmonary hypertension. Moreover, $\mathrm{S}_{\mathrm{pO}_{2}}$ reduction time during 6MWT and recovery time after $6 \mathrm{MWT}$ were slower in subjects with severe chronic thromboembolic pulmonary hypertension than in those with mild chronic thromboembolic pulmonary hypertension.

hypertension, in addition to its pathophysiology, should also be considered (eg, oxygen flow, pulmonary vasodilator, PEA, and deconditioning).

The purpose of our study was to evaluate the relationships between parameters concerning the heart-rate response and oxygen desaturation-resaturation patterns during the 6MWT and the severity of pulmonary hemodynamics in subjects with mild to severe chronic thromboembolic pulmonary hypertension. Additionally, we tested the hypothesis that variables of the 6MWT post-PEA in subjects with severe chronic thromboembolic pulmonary hypertension would return to levels similar to those in subjects with mild chronic thromboembolic pulmonary hypertension.

\section{Methods}

\section{Subject Selection}

We retrospectively enrolled 54 subjects with chronic thromboembolic pulmonary hypertension who had undergone 6MWT, pulmonary function test, diagnostic right heart catheterization, and echocardiography at Chiba University Hospital in Chiba, Japan, between July 2011 and December 2016. Chronic thromboembolic pulmonary hypertension was defined as mean pulmonary arterial pressure $\geq 25 \mathrm{~mm} \mathrm{Hg}$ with normal wedge pressure, as determined by subjects having undergone right heart catheterization with therapeutic anticoagulation for $>3$ months. ${ }^{1}$ 


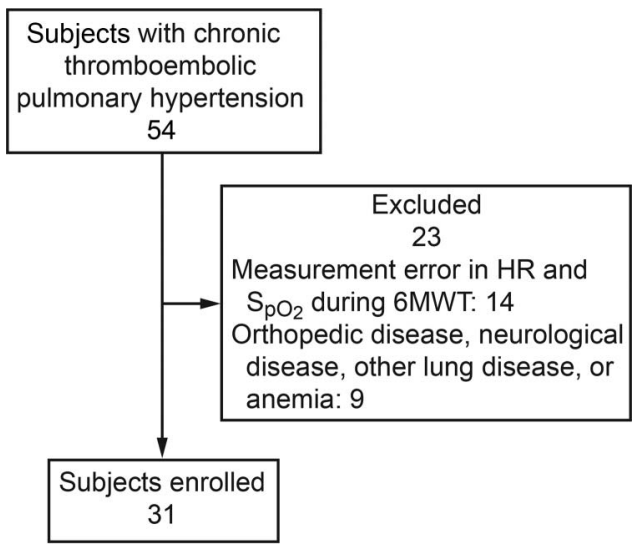

Fig. 1. Flow chart. $\mathrm{HR}=$ heart rate, $6 \mathrm{MWT}=6$-min walk test.

Lung perfusion scans that revealed segmental or larger defects concomitant with normal ventilation scans were also required for diagnosis. Findings suggestive of chronic thromboemboli were confirmed with pulmonary angiography. ${ }^{1,3}$ Subjects with measurement error in pulse rate and $\mathrm{S}_{\mathrm{pO}_{2}}$ during the 6MWT were excluded, as were subjects with orthopedic or neurological disorders, anemia, or active lung diseases other than chronic thromboembolic pulmonary hypertension. A total of 31 subjects were evaluated (Fig. 1). Subjects with chronic thromboembolic pulmonary hypertension were categorized according to disease severity (mild chronic thromboembolic pulmonary hypertension: mean pulmonary arterial pressure $<40 \mathrm{~mm} \mathrm{Hg}$; severe chronic thromboembolic pulmonary hypertension: mean pulmonary arterial pressure $\geq 40 \mathrm{~mm} \mathrm{Hg}$ ). To examine the effects of PEA, 10 of the 31 subjects who had all of the above data both pre- and post-PEA were separately evaluated. The study database was anonymized and complied according to the requirements of the Ministry of Health, Labor, and Welfare, which is dedicated to privacy, information technology, and civil rights in Japan. The Ethics Committee of Chiba University approved the study protocol (approval number 1259).

\section{Pretest Evaluations}

All subjects had undergone baseline hemodynamic testing with right heart catheterization, including measurements of mean pulmonary arterial pressure, systolic pulmonary arterial pressure, diastolic pulmonary arterial pressure, pulmonary vascular resistance, $\mathrm{P}_{\mathrm{aO}}$, mixed venous partial pressure of oxygen $\left(\mathrm{P}_{\overline{\mathrm{v}} \mathrm{O}_{2}}\right)$, mixed venous oxygen saturation $\left(\mathrm{S}_{\overline{\mathrm{v}}_{2}}\right)$, cardiac index, cardiac output, and alveolar-arterial oxygen difference $\left(\mathrm{P}_{(\mathrm{A}-\mathrm{a}) \mathrm{O}_{2}}\right)$. Doppler echocardiography using an AplioTM 300 ultrasound (Toshiba Medical, Tochigi, Japan) with a PST-25BT transducer (2.5 MHz; Toshiba Medical) was performed on all subjects at the end of expiration. ${ }^{13}$
Estimated systolic pulmonary arterial pressure, tricuspid regurgitation pressure gradient, and left ventricular ejection fraction (LVEF) were recorded.

Pulmonary function was assessed with a spirometer (CHSTAC-8900; Chest MI, Tokyo, Japan), and total lung volume and lung diffusion capacity for carbon monoxide $\left(D_{\mathrm{LCO}}\right)$ were then measured per helium dilution and singlebreath methods, respectively, according to the methods described in the American Thoracic Society's 1994 update. ${ }^{14}$

\section{Subject Monitoring/Data Collection in 6MWT}

The 6MWT was performed according to published guidelines. ${ }^{4}$ In the present study, $6 \mathrm{MWT}$ was performed in an indoor corridor (30 $\mathrm{m}$ in length) under quiet conditions. All subjects completed at least one 6MWT before data collection had begun in order to avoid learning effects. ${ }^{4}$ Ambulatory oxygen was permitted during the test if the subject was already on long-term oxygen therapy.

We recorded 6MWD. Pulse rate (PR) and $\mathrm{S}_{\mathrm{pO}_{2}}$ were measured for $2 \mathrm{~min}$ at baseline, continuously during the test, and $3 \mathrm{~min}$ for recovery by finger probe pulse oximeter (Pulsox-300i; Minolta, Tokyo, Japan). Since there were no subjects with obvious arrhythmia in the present study, PR was regarded as heart rate, as described in previous studies. ${ }^{8,9}$ Data were recorded every $1 \mathrm{~s}$ and were transferred to a personal computer. Methods for the calculation of heart rate parameters are shown in Figure 2A. Heart rate at rest and maximal heart rate were evaluated and $\Delta$ heart rate was calculated (maximum heart rate-heart rate at rest). Heart rate acceleration time (time taken to increase to $75 \%$ of $\Delta$ heart rate;) and slope of heart rate acceleration [slope of heart rate until point at which the subject has increased to $75 \%$ of change in heart rate; (75\% of $\Delta$ heart rate)/(heart rate acceleration time)] were also calculated. Heart rate recovery during the first minute after 6MWT (HRR1) was defined as the difference between a subject's heart rate at completion of 6MWT and at $1 \mathrm{~min}$ after completion of 6MWT. ${ }^{9}$ Methods for evaluating $\mathrm{S}_{\mathrm{pO}_{2}}$ parameters are shown in Figure $2 \mathrm{~B} . \mathrm{S}_{\mathrm{pO}_{2}}$ at rest, $\mathrm{S}_{\mathrm{pO}_{2}}$ after 6MWT, and lowest $\mathrm{S}_{\mathrm{pO}_{2}}$ were evaluated and $\Delta \mathrm{S}_{\mathrm{pO}_{2}}$ was calculated (lowest $\mathrm{S}_{\mathrm{pO}_{2}}$ $-\mathrm{S}_{\mathrm{pO}_{2}}$ at rest). Further, $\mathrm{S}_{\mathrm{pO}_{2}}$ reduction time (time taken to decrease $75 \%$ of $\Delta \mathrm{S}_{\mathrm{pO}_{2}}$ ) and $\mathrm{S}_{\mathrm{pO}_{2}}$ recovery time [time taken to recover to $75 \%$ of $\left(\mathrm{S}_{\mathrm{pO}_{2}}\right.$ after $6 \mathrm{MWT}-\mathrm{S}_{\mathrm{pO}_{2}}$ at rest)] were calculated. We also recorded the 10-point-modified Borg scale ${ }^{15}$ score after 6MWT. The 6MWT, right heart catheterization, echocardiography, and pulmonary function were measured during the same hospitalization for diagnosis and follow-up within 1-2 weeks.

\section{Statistical Analysis}

Data are presented as mean $\pm \mathrm{SD}$. Differences in mean values between the 2 groups (ie, mild vs severe chronic 

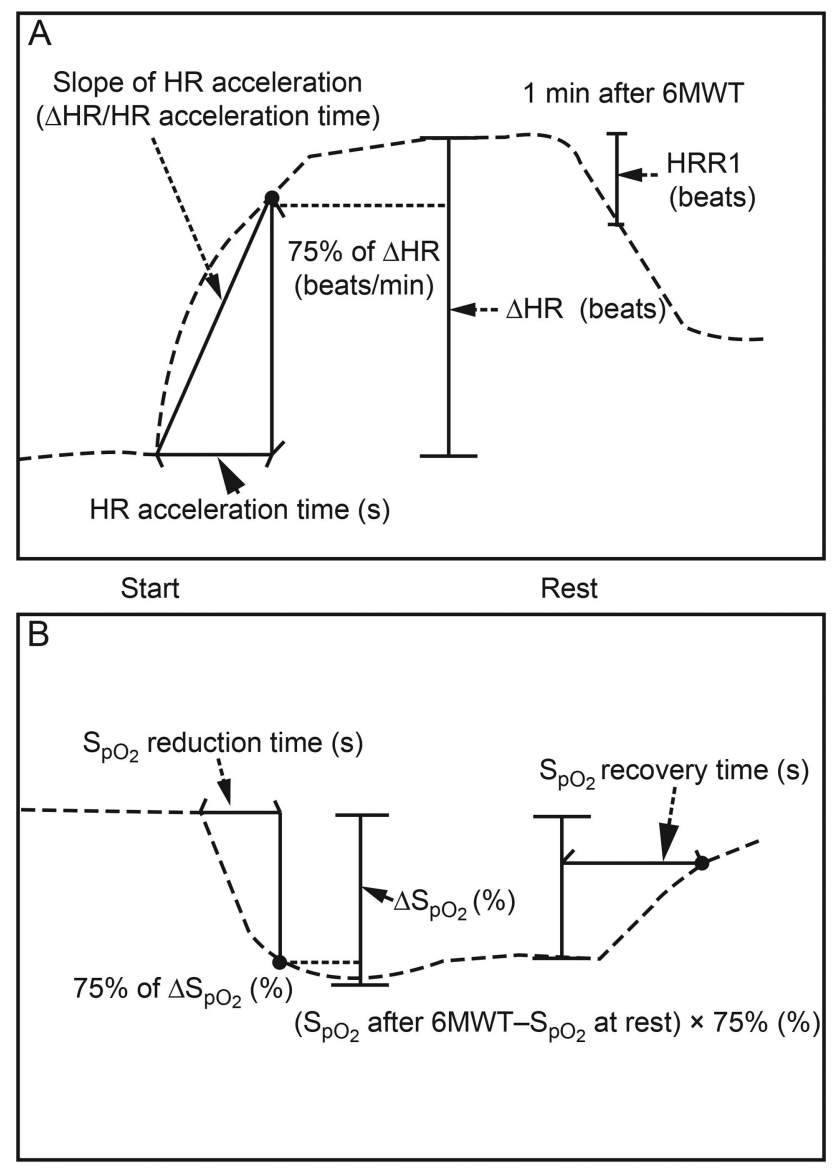

Start

Rest

Fig. 2. Methods for calculation of pulse rate $(A)$ and $\mathrm{S}_{\mathrm{pO}_{2}}$ (B) parameters during 6-min walk test (6MWT). A: $\Delta \mathrm{HR}$ was defined as maximum HR - HR at rest. HR acceleration time was defined as the time taken to increase to $75 \%$ of $\Delta \mathrm{HR}$. Slope of HR acceleration was defined as $75 \%$ of $\Delta \mathrm{HR} / \mathrm{HR}$ acceleration time. HRR1 was defined as the difference between a subject's heart rate at completion of the $6 \mathrm{MWT}$ and at $1 \mathrm{~min}$ after completion of the 6MWT. B: Methods for calculation of $\mathrm{SpO} 2$ during $6 \mathrm{MWT}$. $\Delta \mathrm{S}_{\mathrm{pO}_{2}}$ was defined as lowest $\mathrm{S}_{\mathrm{pO}_{2}}-\mathrm{S}_{\mathrm{pO}_{2}}$ at rest. $\mathrm{S}_{\mathrm{pO}_{2}}$ reduction time was defined as the time taken to decrease to $75 \%$ of $\Delta \mathrm{S}_{\mathrm{pO}_{2}} . \mathrm{S}_{\mathrm{pO}_{2}}$ recovery time was defined as the time taken to recover to $75 \%$ of $\left(\mathrm{S}_{\mathrm{pO}_{2}}\right.$ after $6 \mathrm{MWT}-\mathrm{S}_{\mathrm{pO}_{2}}$ at rest). $\mathrm{HR}=$ heart rate, $\mathrm{HRR} 1$ = recovery during the first minute after $6 \mathrm{MWT}$.

thromboembolic pulmonary hypertension) were assessed with the Mann-Whitney U-test. Spearman's rank correlation coefficient was used to evaluate the relationship between the 6MWT parameters and age, physical parameters, right heart catheterization parameters, echocardiographic parameters, and pulmonary function parameters. Multiple linear regression analyses were performed to evaluate the independent association between the 6MWT parameters and right heart catheterization, echocardiographic, and pulmonary function parameters. In this analysis, clinical factors to which the 6MWT parameters were significantly correlated were included in the univariate regression analysis. In subjects who received PEA thereafter, intragroup comparisons (pre-PEA vs post-PEA) were made using the Wilcoxon signed-rank test for 6MWT parameters. The number of cases during the study period determined the sample size. Values of $P<.05$ were considered statistically significant. All analyses were carried out with the JMP10.0 software program (SAS institute, Cary, North Carolina).

\section{Results}

\section{Subject Characteristics}

Our study included 31 subjects with chronic thromboembolic pulmonary hypertension (World Health Organization functional class I, $n=3$; class II, $n=17$; class III, $n=10$; class IV, $n=1) .{ }^{16}$ Baseline characteristics of subjects are shown in Table 1. Nineteen subjects (61.3\%) had received long-term oxygen therapy. The mean prescribed oxygen flow was $2.3 \mathrm{~L}$ during exercise. No subjects were using $\beta$-blockers.

\section{MWT Parameters According to Severity of Chronic Thromboembolic Pulmonary Hypertension}

Table 2 shows the 6MWT parameters for our sample of 31 subjects with chronic thromboembolic pulmonary hypertension. Compared with subjects with mild chronic thromboembolic pulmonary hypertension, subjects with severe chronic thromboembolic pulmonary hypertension had shorter 6MWD. Subjects with severe chronic thromboembolic pulmonary hypertension had significantly longer heart rate acceleration times $(144.9 \pm 63.9 \mathrm{~s}$ vs $96.0 \pm 42.5 \mathrm{~s}, P=.033)$ and lower $\Delta$ heart rate $(47.4 \pm 16.9$ beats $/ \mathrm{min}$ vs $61.8 \pm 13.6$ beats $/ \mathrm{min}$, $P=.02)$, lower slope of heart rate acceleration $(0.3 \pm 0.1 \mathrm{vs}$ $0.7 \pm 0.4, P<.001)$, lower HRR1 $(13.3 \pm 9.0$ beats vs $27.1 \pm 9.2$ beats, $P<.001)$. Heart rate at rest tended to be higher in subjects with severe chronic thromboembolic pulmonary hypertension than in those with mild chronic thromboembolic pulmonary hypertension, but this difference was not significant ( $77.4 \pm 11.4$ beats/min vs $69.5 \pm 7.1$ beats/ $\min , P=.08$ ). Subjects with severe chronic thromboembolic pulmonary hypertension had significantly longer $\mathrm{S}_{\mathrm{pO}_{2}}$ reduction times $(178.3 \pm 70.3 \mathrm{~s}$ vs $134.3 \pm 58.4 \mathrm{~s}, P=.025)$ and $\mathrm{S}_{\mathrm{pO}_{2}}$ recovery times $(107.6 \pm 35.3 \mathrm{~s}$ vs $69.8 \pm 32.7 \mathrm{~s}, P=.004)$ than did subjects with mild chronic thromboembolic pulmonary hypertension.

Figure 3 presents sequential mean changes of heart rate and $\mathrm{S}_{\mathrm{pO}_{2}}$ during the 6MWT for subjects with mild versus severe chronic thromboembolic pulmonary hypertension. In subjects with severe chronic thromboembolic pulmonary hypertension, heart rate increased slowly compared to those with mild chronic thromboembolic pulmonary hypertension. Subjects with severe chronic thromboembolic pulmonary hypertension continued desaturating throughout the 6MWT, while in subjects with mild chronic thromboembolic 
Table 1. Baseline Characteristics of Subjects With Chronic Thromboembolic Pulmonary Hypertension

\begin{tabular}{|c|c|}
\hline Characteristics & Values \\
\hline Females/males, $n$ & $27 / 4$ \\
\hline Age, y & $59.9 \pm 10.1$ \\
\hline Height, cm & $154.4 \pm 8.0$ \\
\hline Weight, kg & $51.5 \pm 7.5$ \\
\hline Body mass index, $\mathrm{kg} / \mathrm{m}^{2}$ & $21.6 \pm 2.7$ \\
\hline$\%$ Ideal body weight & $98.1 \pm 12.1$ \\
\hline Long-term oxygen therapy, $n$ & $19(61.3 \%)$ \\
\hline WHO functional class (I/II/III/IV), $n$ & $(3 / 17 / 10 / 1)$ \\
\hline \multicolumn{2}{|l|}{ Right heart catheterization } \\
\hline Mean pulmonary artery pressure, $\mathrm{mm} \mathrm{Hg}$ & $41.6 \pm 11.2$ \\
\hline Systolic pulmonary artery pressure, $\mathrm{mm} \mathrm{Hg}$ & $75.2 \pm 23.2$ \\
\hline Diastolic pulmonary artery pressure, $\mathrm{mm} \mathrm{Hg}$ & $21.8 \pm 8.0$ \\
\hline Pulmonary vascular resistance, Wood units & $8.1 \pm 3.6$ \\
\hline $\mathrm{P}_{\mathrm{aO}_{2}}, \mathrm{~mm} \mathrm{Hg}$ & $57.6 \pm 9.1$ \\
\hline $\mathrm{P}_{\overline{\mathrm{v}} \mathrm{O}_{2}}, \mathrm{~mm} \mathrm{Hg}$ & $35.4 \pm 5.9$ \\
\hline $\mathrm{S}_{\overline{\mathrm{v}} \mathrm{O}_{2}}, \%$ & $63.8 \pm 8.3$ \\
\hline Cardiac index, $\mathrm{L} / \mathrm{min} / \mathrm{m}^{2}$ & $3.0 \pm 0.7$ \\
\hline Cardiac output, $\mathrm{L} / \mathrm{min}$ & $4.5 \pm 1.0$ \\
\hline $\mathrm{P}_{(\mathrm{A}-\mathrm{a}) \mathrm{O}_{2}}, \mathrm{~mm} \mathrm{Hg}$ & $46.3 \pm 9.5$ \\
\hline \multicolumn{2}{|l|}{ Echocardiography } \\
\hline Systolic pulmonary artery pressure, $\mathrm{mm} \mathrm{Hg}$ & $71.4 \pm 23.3$ \\
\hline TRPG, mm Hg & $66.2 \pm 23.5$ \\
\hline LVEF, \% & $74.0 \pm 8.3$ \\
\hline \multicolumn{2}{|l|}{ Pulmonary functions } \\
\hline $\mathrm{VC}, \%$ predicted & $86.3 \pm 12.8$ \\
\hline $\mathrm{FEV}_{1}, \%$ predicted & $86.9 \pm 15.5$ \\
\hline $\mathrm{FEV}_{1} / \mathrm{FVC}, \%$ & $76.5 \pm 7.3$ \\
\hline $\mathrm{D}_{\mathrm{LCO}}, \%$ predicted & $70.7 \pm 14.0$ \\
\hline $\mathrm{D}_{\mathrm{LCO}} / \mathrm{V}_{\mathrm{A}}, \%$ predicted & $80.6 \pm 12.7$ \\
\hline TLC, $\%$ predicted & $97.6 \pm 11.0$ \\
\hline \multicolumn{2}{|l|}{$\begin{array}{l}\text { Data are presented as } n(\%) \text { or mean } \pm \text { SD. } N=31 . \\
\text { WHO = World Health Organization }\end{array}$} \\
\hline \multicolumn{2}{|l|}{$\begin{array}{l}\text { WHO = World Health Organization } \\
\mathrm{P}_{2}=\text { arterial partial pressure of oxygen }\end{array}$} \\
\hline \multicolumn{2}{|l|}{$\begin{array}{l}\mathrm{aO}_{2}=\text { med venous partial pressure of oxygen } \\
\mathrm{P}_{\mathrm{v}_{\mathrm{O}}}=\text { mixed val }\end{array}$} \\
\hline \multicolumn{2}{|l|}{$\mathrm{S}_{\mathrm{v}_{2}}=$ mixed venous oxygen saturation } \\
\hline \multicolumn{2}{|l|}{$\mathrm{P}_{(\mathrm{A}-\mathrm{2}) \mathrm{O}_{2}}=$ alveolar-arterial oxygen difference } \\
\hline \multicolumn{2}{|l|}{ 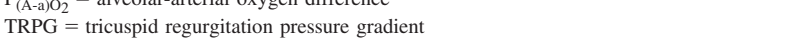 } \\
\hline \multicolumn{2}{|l|}{ LVEF = left-ventricular ejection fraction } \\
\hline \multicolumn{2}{|l|}{$\mathrm{VC}=$ vital capacity } \\
\hline \multicolumn{2}{|l|}{$\mathrm{D}_{\mathrm{LCO}}=$ lung diffusion capacity for carbon monoxide } \\
\hline \multirow{2}{*}{\multicolumn{2}{|c|}{$\begin{array}{l}\mathrm{D}_{\mathrm{LCO}} / \mathrm{V}_{\mathrm{A}}=\text { lung diffusion capacity divided by alveolar volume } \\
\mathrm{TLC}=\text { total lung capacity }\end{array}$}} \\
\hline & \\
\hline
\end{tabular}

pulmonary hypertension the $\mathrm{S}_{\mathrm{pO}_{2}}$ decreased during the first $3 \mathrm{~min}$ and then remained stable during the 6MWT.

\section{Independent Associations of Severe Chronic Thromboembolic Pulmonary Hypertension in 6MWT Parameters}

Correlations between the 6MWT parameters and clinical factors are shown in Table 3. Heart rate acceleration time was mainly positively correlated with mean pulmonary arterial pressure $(\mathrm{r}=0.47, P=.008)$ and negatively correlated with $\mathrm{CO}(\mathrm{r}=-0.41, P=.02)$. The slope of heart rate acceleration was mainly negatively correlated with mean pulmonary arterial pressure $(\mathrm{r}=-0.67$, $P<.001)$ and positively correlated with $\mathrm{CO}(\mathrm{r}=0.37$, $P=.041)$. The $\Delta$ heart rate was mainly negatively correlated with mean pulmonary arterial pressure $(\mathrm{r}=-0.39$, $P=.032$ ), although this correlation was weak. The 6MWD was mainly negatively correlated with mean pulmonary arterial pressure $(\mathrm{r}=-0.61, P<.001)$ and positively correlated with total lung capacity $(\mathrm{r}=0.69, P<.001)$. HRR1 was mainly negatively correlated with mean pulmonary arterial pressure $(\mathrm{r}=-0.56, P=.001)$ and positively correlated with $\mathrm{D}_{\mathrm{LCO}} / \mathrm{V}_{\mathrm{A}}(\mathrm{r}=0.47, P=.008)$. The $\mathrm{S}_{\mathrm{pO}_{2}}$ reduction time was mainly positively correlated with mean pulmonary arterial pressure $(\mathrm{r}=0.43, P=.02)$ and negatively correlated with $\mathrm{CO}(\mathrm{r}=-0.42, P=.02)$ and $\operatorname{LVEF}(\mathrm{r}=-0.45, P=.01)$. The $\mathrm{S}_{\mathrm{pO}_{2}}$ recovery time was mainly positively correlated with mean pulmonary arterial pressure $(\mathrm{r}=0.61, P<.001)$ and negatively correlated with $\mathrm{D}_{\mathrm{LCO}} / \mathrm{V}_{\mathrm{A}}(\mathrm{r}=-0.43, P=.02)$. Age was not significantly correlated with the 6MWT parameters.

Multivariate linear regression analyses are shown in Table 4 . The heart rate acceleration time and slope of heart rate acceleration were independently associated with mean pulmonary arterial pressure. $\mathrm{HRR} 1$ and $\mathrm{S}_{\mathrm{pO}_{2}}$ recovery time were independently associated with mean pulmonary arterial pressure and $\mathrm{D}_{\mathrm{LCO}} / \mathrm{V}_{\mathrm{A}}$. The $\mathrm{S}_{\mathrm{pO}_{2}}$ reduction time and the 6MWD were not independently associated with mean pulmonary arterial pressure.

\section{Effects of PEA}

The effects of PEA on 6MWT parameters are presented in Table 5. We analyzed changes in 6MWT parameters $1 \mathrm{y}$ post-PEA in 10 of the 17 subjects who underwent PEA, because 7 subjects had measurement error in heart rate and/or $\mathrm{S}_{\mathrm{pO}_{2}}$ during the 6MWT. Post-PEA, mean pulmonary arterial pressure, systolic pulmonary arterial pressure, and pulmonary vascular resistance decreased significantly, and $\mathrm{S}_{\overline{\mathrm{v}}_{2}}$ increased significantly. The 6MWD and heart rate at rest increased post-PEA. Other parameters were unchanged, except for 1 subject whose post-PEA mean pulmonary arterial pressure decreased (from $32 \mathrm{~mm} \mathrm{Hg}$ to $13 \mathrm{~mm} \mathrm{Hg}$ ), $\Delta$ heart rate increased (from 43 beats/min to 72 beats/min), slope of heart rate acceleration increased (from 0.3 to 1.1), HRR1 increased (from 25 beats to 48 beats), heart rate acceleration time decreased (from $136 \mathrm{~s}$ to $65 \mathrm{~s}$ ), and $\mathrm{S}_{\mathrm{pO}_{2}}$ recovery time decreased (from $123 \mathrm{~s}$ to $42 \mathrm{~s}$ ), in addition to the increase in the 6MWD (from $394 \mathrm{~m}$ to $571 \mathrm{~m})$.

\section{Discussion}

This study has several important findings regarding changes in patterns of heart rate and $\mathrm{S}_{\mathrm{pO}_{2}}$ in chronic thromboembolic 
Table 2. Data for All Outcomes During 6MWT in Subjects With Chronic Thromboembolic Pulmonary Hypertension

\begin{tabular}{|c|c|c|c|c|}
\hline Outcomes & All Subjects $(N=31)$ & Mild $(n=12)$ & Severe $(n=19)$ & $P$ \\
\hline 6-min walk distance, $\mathrm{m}$ & $410.8 \pm 73.7$ & $462.6 \pm 52.6$ & $378.1 \pm 66.8$ & .002 \\
\hline Heart rate at rest, beats/min & $74.3 \pm 10.6$ & $69.5 \pm 7.1$ & $77.4 \pm 11.4$ & .08 \\
\hline Heart rate after $6 \mathrm{MWT}$, beats/min & $120.2 \pm 16.2$ & $123.3 \pm 17.6$ & $118.2 \pm 15.4$ & .70 \\
\hline Maximum heart rate, beats/min & $127.3 \pm 16.5$ & $131.3 \pm 17.2$ & $124.8 \pm 16.0$ & .45 \\
\hline$\Delta$ Heart rate, beats & $53.0 \pm 17.0$ & $61.8 \pm 13.6$ & $47.4 \pm 16.9$ & .02 \\
\hline Heart rate acceleration time, $\mathrm{s}$ & $126.0 \pm 60.9$ & $96.0 \pm 42.5$ & $144.9 \pm 63.9$ & .033 \\
\hline Slope of increased heart rate & $0.6 \pm 0.5$ & $0.7 \pm 0.4$ & $0.3 \pm 0.1$ & $<.001$ \\
\hline HRR1, beats & $18.6 \pm 11.2$ & $27.1 \pm 9.2$ & $13.3 \pm 9.0$ & $<.001$ \\
\hline $\mathrm{S}_{\mathrm{pO}_{2}}$ at rest, $\%$ & $96.3 \pm 1.9$ & $96.2 \pm 1.9$ & $96.4 \pm 1.9$ & .76 \\
\hline $\mathrm{S}_{\mathrm{pO}_{2}}$ after $6 \mathrm{MWT}, \%$ & $87.6 \pm 4.4$ & $88.5 \pm 2.6$ & $87.0 \pm 5.3$ & .50 \\
\hline Lowest $\mathrm{S}_{\mathrm{pO}_{2}}$ during $6 \mathrm{MWT}, \%$ & $86.1 \pm 4.2$ & $86.5 \pm 2.2$ & $85.9 \pm 5.1$ & $>.99$ \\
\hline$\Delta \mathrm{S}_{\mathrm{pO}_{2}}, \%$ & $-10.2 \pm 4.2$ & $-8.1 \pm 2.6$ & $-9.6 \pm 5.2$ & .38 \\
\hline $\mathrm{S}_{\mathrm{pO}_{2}}$ reduction time, $\mathrm{s}$ & $169.4 \pm 78.8$ & $134.3 \pm 58.4$ & $178.3 \pm 70.3$ & .03 \\
\hline $\mathrm{S}_{\mathrm{pO}_{2}}$ recovery time, $\mathrm{s}$ & $93.0 \pm 38.6$ & $69.8 \pm 32.7$ & $107.6 \pm 35.3$ & .004 \\
\hline Dyspnea after 6MWT, Borg score & $3.3 \pm 1.6$ & $3.2 \pm 1.5$ & $3.4 \pm 1.6$ & .65 \\
\hline
\end{tabular}

$\overline{\text { Data are presented as }}$ mean \pm SD. Differences calculated using Mann-Whitney $U$-tests.

$6 \mathrm{MWT}=6$-min walk test

HRR1 = heart rate recovery $1 \mathrm{~min}$ after completing $6 \mathrm{MWT}$
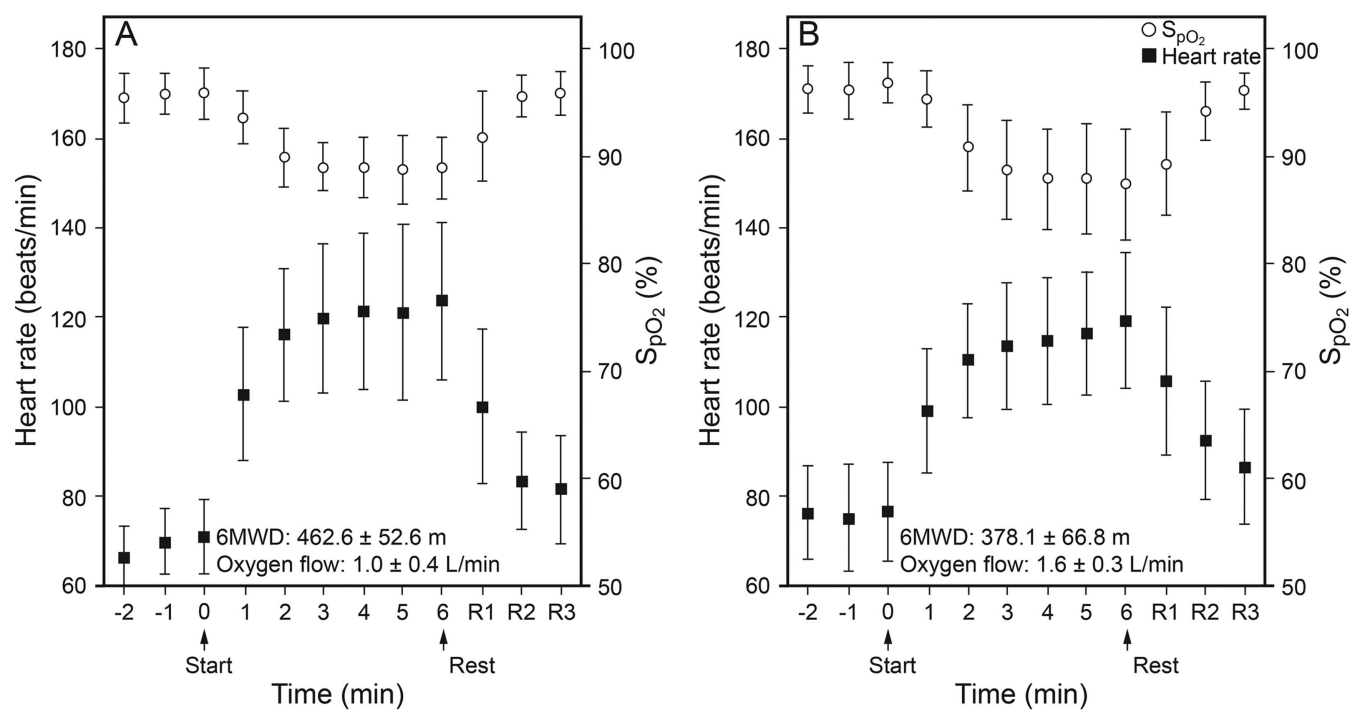

Fig. 3. Sequential changes in heart rate and $\mathrm{S}_{\mathrm{pO}_{2}}$ during 6MWT (mean $\pm \mathrm{SD}$ ). In subjects with severe chronic thromboembolic pulmonary hypertension $(\mathrm{B})$, heart rate increased slowly compared to subjects with mild chronic thromboembolic pulmonary hypertension $(\mathrm{A})$. $\mathrm{S}_{\mathrm{pO}}$ decreased during the first $3 \mathrm{~min}$ and then remained stable during $6 \mathrm{MWT}$ in subjects with mild chronic thromboembolic pulmonary hypertension, while subjects with severe chronic thromboembolic pulmonary hypertension continued desaturating throughout 6MWT. $\mathrm{HR}=$ heart rate, $6 \mathrm{MWT}=6-\mathrm{min}$ walk test, $6 \mathrm{MWD}=6-\mathrm{min}$ walk distance.

pulmonary hypertension. Heart rate acceleration was slower, the slope of heart rate was less steep during the 6MWT, and HRR1 was lower after 6MWT in subjects with severe chronic thromboembolic pulmonary hypertension than in those with mild chronic thromboembolic pulmonary hypertension. Additionally, the $\mathrm{S}_{\mathrm{pO}_{2}}$ reduction time during the 6MWT and recovery time after the 6MWT were slower in subjects with severe chronic thromboembolic pulmonary hypertension than in those with mild chronic thromboembolic pulmonary hypertension. Importantly, the heart rate acceleration time and slope of heart rate were associated with pulmonary hemodynamics in subjects with chronic thromboembolic pulmonary hypertension.

These results in subjects with severe chronic thromboembolic pulmonary hypertension are consistent with recent studies for PAH, demonstrating small and slow heartrate change during and after the 6MWT in subjects with 
Table 3. Correlations Between Outcomes During 6MWT and Clinical Data in Subjects With Chronic Thromboembolic Pulmonary Hypertension

\begin{tabular}{|c|c|c|c|c|c|c|c|}
\hline & 6MWD & $\begin{array}{l}\Delta \text { Heart } \\
\text { Rate }\end{array}$ & $\begin{array}{c}\text { Heart Rate } \\
\text { Acceleration Time }\end{array}$ & $\begin{array}{c}\text { Slope of } \\
\text { Heart Rate } \\
\text { Acceleration }\end{array}$ & $\begin{array}{l}\text { HRR1, } \\
\text { beats }\end{array}$ & $\begin{aligned} \mathrm{S}_{\mathrm{pO}_{2}} & \text { Reduction } \\
& \text { Time }\end{aligned}$ & $\begin{array}{c}\mathrm{S}_{\mathrm{pO}_{2}} \text { Recovery } \\
\text { Time }\end{array}$ \\
\hline Age & -0.33 & -0.07 & 0.07 & -0.21 & -0.17 & -0.11 & 0.01 \\
\hline Height & $0.36^{*}$ & 0.07 & -0.14 & 0.25 & 0.19 & 0.05 & -0.05 \\
\hline Weight & $0.42 *$ & 0.33 & 0.03 & 0.20 & 0.25 & -0.19 & -0.17 \\
\hline Mean pulmonary artery pressure & $-0.61 * *$ & $-0.39 *$ & $0.47 * *$ & $-0.67 * *$ & $-0.56^{* *}$ & $0.43^{*}$ & $0.61 * *$ \\
\hline Systolic pulmonary artery pressure & $-0.61 * *$ & $-0.38^{*}$ & $0.53 * *$ & $-0.69 * *$ & $-0.52 * *$ & $0.50 * *$ & $0.60 * *$ \\
\hline Pulmonary vascular resistance & -0.30 & -0.26 & $0.45^{*}$ & $-0.55^{* *}$ & $-0.52 * *$ & $0.50 * *$ & 0.31 \\
\hline $\mathrm{P}_{\overline{\mathrm{v}} \mathrm{O}_{2}}$ & $0.52 * *$ & 0.31 & $-0.36^{*}$ & $0.44 *$ & 0.35 & -0.23 & -0.33 \\
\hline $\mathrm{S}_{\overline{\mathrm{v}}_{2}}$ & 0.15 & 0.11 & -0.27 & 0.18 & 0.25 & -0.14 & $-0.43^{*}$ \\
\hline Cardiac output & 0.08 & 0.11 & $-0.41^{*}$ & $0.37 *$ & 0.30 & $-0.42 *$ & -0.14 \\
\hline $\mathrm{P}_{(\mathrm{A}-\mathrm{a}) \mathrm{O}_{2}}$ & $-0.48 * *$ & -0.27 & 0.04 & -0.24 & -0.31 & 0.02 & 0.33 \\
\hline TRPG & $-0.55^{* *}$ & -0.16 & $0.47 * *$ & $-0.43^{*}$ & -0.34 & $0.38^{*}$ & $0.57 * *$ \\
\hline LVEF & 0.00 & 0.15 & 0.01 & 0.06 & 0.30 & $-0.45^{*}$ & -0.20 \\
\hline $\mathrm{VC}, \%$ pred & $0.61 * *$ & $0.37 *$ & -0.10 & 0.30 & $0.38^{*}$ & -0.17 & $-0.44^{*}$ \\
\hline $\mathrm{FEV}_{1}, \%$ pred & $0.62 * *$ & $0.36^{*}$ & -0.33 & $0.48 * *$ & $0.40^{*}$ & $-0.39 *$ & $-0.38 *$ \\
\hline $\mathrm{FEV}_{1} / \mathrm{FVC}, \%$ & 0.21 & 0.15 & -0.26 & 0.31 & 0.22 & -0.17 & -0.13 \\
\hline $\mathrm{D}_{\mathrm{LCO}}, \%$ pred & 0.29 & 0.20 & -0.06 & 0.17 & $0.53 * *$ & 0.09 & $-0.54 * *$ \\
\hline $\mathrm{D}_{\mathrm{LCO}} / \mathrm{V}_{\mathrm{A}}, \%$ pred & 0.20 & 0.28 & -0.02 & 0.16 & $0.47 * *$ & 0.16 & $-0.43^{*}$ \\
\hline TLC, $\%$ pred & $0.69 * *$ & 0.29 & -0.23 & $0.43^{*}$ & 0.34 & 0.02 & $-0.47 * *$ \\
\hline $\begin{array}{l}\text { Data are expressed as } r \text { value. } N=31 . \\
* P<.05, * * P<.01 \text { compared with baseline. } \\
6 \mathrm{MWD}=6 \text {-min walk distance } \\
\mathrm{HRR} 1=\text { heart rate recovery } 1 \text { min after compl } \\
\mathrm{P}_{\mathrm{V}_{2} \mathrm{O}_{2}}=\text { mixed venous oxygen pressure } \\
\mathrm{S}_{\mathrm{V}_{2}}=\text { mixed venous oxygen saturation } \\
\mathrm{P}_{\mathrm{P}_{2}-\mathrm{A}_{2}=\text { alveolar-arterial oxygen difference }} \\
\mathrm{TRPG}=\text { tricuspid regurgitation pressure gradie } \\
\mathrm{LVEF}=\text { left-ventricular ejection fraction } \\
\mathrm{VC}=\text { vital capacity } \\
\mathrm{D}_{\mathrm{LCO}}=\text { lung diffusion capacity for carbon mor } \\
\mathrm{D}_{\mathrm{LCO}} / \mathrm{V}_{\mathrm{A}}=\text { lung diffusion capacity divided by } \\
\mathrm{TLC}=\text { total lung capacity }\end{array}$ & $\begin{array}{l}\text { ide } \\
\text { eolar volume }\end{array}$ & & & & & & \\
\hline
\end{tabular}

Table 4. Multivariate Linear Regression Analysis Between Outcomes During 6MWT and Clinical Data in Subjects With Chronic Thromboembolic Pulmonary Hypertension

\begin{tabular}{|c|c|c|c|c|c|c|c|c|c|c|c|c|}
\hline & \multicolumn{2}{|c|}{ 6MWD } & \multicolumn{2}{|c|}{$\begin{array}{l}\text { Heart Rate } \\
\text { Acceleration } \\
\text { Time }\end{array}$} & \multicolumn{2}{|c|}{$\begin{array}{c}\text { Slope of } \\
\text { Heart Rate } \\
\text { Acceleration }\end{array}$} & \multicolumn{2}{|c|}{$\begin{array}{c}\text { HRR1, } \\
\text { beats }\end{array}$} & \multicolumn{2}{|c|}{$\begin{array}{c}\mathrm{S}_{\mathrm{pO}_{2}} \text { Reduction } \\
\text { Time }\end{array}$} & \multicolumn{2}{|c|}{$\begin{array}{c}\mathrm{S}_{\mathrm{pO}_{2}} \text { Recovery } \\
\text { Time }\end{array}$} \\
\hline & $\beta$ & $P$ & $\beta$ & $P$ & $\beta$ & $P$ & $\beta$ & $P$ & $\beta$ & $P$ & $\beta$ & $P$ \\
\hline Mean pulmonary artery pressure & & & 0.38 & .032 & -0.50 & .02 & -0.51 & $<.003$ & & & 0.48 & .01 \\
\hline Cardiac output & & & & & & & & & -0.40 & .03 & & \\
\hline LVEF & & & & & & & & & -0.42 & .01 & & \\
\hline $\mathrm{D}_{\mathrm{LCO}} / \mathrm{V}_{\mathrm{A}}, \%$ pred & & & & & & & 0.35 & .030 & & & -0.39 & .01 \\
\hline TLC, $\%$ pred & 0.27 & .02 & & & & & & & & & & \\
\hline $\begin{array}{l}N=31 . \\
6 \mathrm{MWD}=6 \text {-min walk distance } \\
\mathrm{HRR} 1=\text { heart rate recovery } 1 \text { min after com } \\
\mathrm{LVEF}=\text { left-ventricular ejection fraction } \\
\mathrm{D}_{\mathrm{LCO}} / \mathrm{V}_{\mathrm{A}}=\text { lung diffusion capacity divided } \\
\mathrm{TLC}=\text { total lung capacity }\end{array}$ & leting 6N & NT & & & & & & & & & & \\
\hline
\end{tabular}


Table 5. Changes in 6MWT Characteristics Observed 1 Y Post PEA in Subjects With Chronic Thromboembolic Pulmonary Hypertension

\begin{tabular}{|c|c|c|c|}
\hline Outcomes $(n=10)$ & Pre-PEA & Post-PEA & $P$ \\
\hline \multicolumn{4}{|l|}{ 6MWT parameters } \\
\hline 6-min walking distance, $\mathrm{m}$ & $403.2 \pm 83.6$ & $458.5 \pm 111.1$ & .039 \\
\hline Heart rate at rest, bpm & $70.7 \pm 11.9$ & $81.4 \pm 10.9$ & .039 \\
\hline Heart rate after 6MWT, bpm & $115.5 \pm 17.8$ & $121.3 \pm 16.1$ & .43 \\
\hline Maximum heart rate, bpm & $122.3 \pm 19.0$ & $127.0 \pm 20.7$ & .50 \\
\hline$\Delta$ Heart rate, beats & $44.8 \pm 16.5$ & $39.9 \pm 17.9$ & .20 \\
\hline Heart rate acceleration time, $\mathrm{s}$ & $121.1 \pm 39.9$ & $121.2 \pm 57.1$ & .94 \\
\hline Slope of heart rate acceleration & $0.4 \pm 0.2$ & $0.4 \pm 0.3$ & .38 \\
\hline HRR1, beats & $22.7 \pm 10.1$ & $20.1 \pm 12.2$ & .50 \\
\hline $\mathrm{S}_{\mathrm{pO}_{2}}$ at rest, $\%$ & $96.2 \pm 1.9$ & $96.8 \pm 1.1$ & .69 \\
\hline $\mathrm{S}_{\mathrm{pO}_{2}}$ after $6 \mathrm{MWT}, \%$ & $88.6 \pm 3.6$ & $91.4 \pm 3.8$ & .25 \\
\hline Lowest $\mathrm{S}_{\mathrm{pO}_{2}}$ during $6 \mathrm{MWT}, \%$ & $87.2 \pm 3.4$ & $88.9 \pm 3.5$ & .27 \\
\hline$\Delta \mathrm{S}_{\mathrm{pO}_{2}}, \%$ & $-7.6 \pm 2.9$ & $-5.4 \pm 3.0$ & .20 \\
\hline $\mathrm{S}_{\mathrm{pO}_{2}}$ reduction time, $\mathrm{s}$ & $162.2 \pm 79.3$ & $193.3 \pm 80.8$ & .31 \\
\hline $\mathrm{S}_{\mathrm{pO}_{2}}$ recovery time, $\mathrm{s}$ & $89.0 \pm 40.3$ & $62.8 \pm 32.7$ & .31 \\
\hline Dyspnea after 6MWT, Borg score & $3.0 \pm 1.7$ & $2.6 \pm 1.5$ & .47 \\
\hline \multicolumn{4}{|l|}{ Right heart catheterization } \\
\hline Mean pulmonary artery pressure, $\mathrm{mm} \mathrm{Hg}$ & $38.7 \pm 8.0$ & $23.1 \pm 11.3$ & .008 \\
\hline Systolic pulmonary artery pressure, $\mathrm{mm} \mathrm{Hg}$ & $70.5 \pm 14.2$ & $40.1 \pm 19.6$ & .008 \\
\hline Pulmonary vascular resistance, Wood units & $7.3 \pm 2.6$ & $3.1 \pm 2.1$ & .008 \\
\hline $\mathrm{P}_{\mathrm{aO}_{2}}, \mathrm{~mm} \mathrm{Hg}$ & $57.5 \pm 7.1$ & $70.1 \pm 15.8$ & .006 \\
\hline $\mathrm{P}_{\mathrm{aCO}_{2}}, \mathrm{~mm} \mathrm{Hg}$ & $36.6 \pm 3.6$ & $41.0 \pm 4.9$ & .008 \\
\hline $\mathrm{P}_{\overline{\mathrm{v}} \mathrm{O}_{2}}, \mathrm{~mm} \mathrm{Hg}$ & $34.6 \pm 3.5$ & $37.5 \pm 2.9$ & .063 \\
\hline $\mathrm{S}_{\overline{\mathrm{v}}_{2}}, \%$ & $63.7 \pm 7.1$ & $69.6 \pm 6.0$ & .031 \\
\hline Cardiac output, $\mathrm{L} / \mathrm{min}$ & $4.4 \pm 1.1$ & $4.2 \pm 0.5$ & .94 \\
\hline \multicolumn{4}{|l|}{ Agent } \\
\hline Bosentan & $1(10.0)$ & $0(0)$ & NA \\
\hline Ambrisentan & $2(20.0)$ & $0(0)$ & NA \\
\hline Sildenafil & $5(50.0)$ & $1(10.0)$ & NA \\
\hline Tadalafil & $3(30.0)$ & $1(10.0)$ & NA \\
\hline Warfarin potassium & $10(100)$ & $0(0)$ & NA \\
\hline Riociguat & $1(10.0)$ & $0(0)$ & NA \\
\hline \multicolumn{4}{|l|}{ Drug combination therapy } \\
\hline No therapy & $1(10.0)$ & $8(80.0)$ & NA \\
\hline Monotherapy & $7(60.0)$ & $2(20.0)$ & NA \\
\hline Dual therapy & $2(20.0)$ & $0(0)$ & NA \\
\hline Long-term oxygen therapy & $7(70)$ & $5(50)$ & NA \\
\hline $\begin{array}{l}\text { Data are presented as mean } \pm \text { SD or } n(\%) \text {. Differences calcul } \\
\mathrm{PEA}=\text { pulmonary endarterectomy } \\
6 \mathrm{MWT}=6 \text {-min walk test } \\
\mathrm{HRR} 1 \text { = heart rate recovery } 1 \text { min after completing } 6 \mathrm{MWT} \\
\mathrm{P}_{\mathrm{aO}_{2}}=\text { arterial partial pressure of oxygen } \\
\mathrm{P}_{\mathrm{aCO}} \text { = arterial partial pressure of carbon dioxide } \\
\mathrm{P}_{\mathrm{vO}_{2}}=\text { mixed venous partial pressure of oxygen } \\
\mathrm{S}_{\mathrm{vO}_{2}}=\text { mixed venous oxygen saturation } \\
\mathrm{NA}=\text { not applicable }\end{array}$ & ank test. & & \\
\hline
\end{tabular}

PAH. ${ }^{10,17-22}$ The mechanics of this chronotropic incompetence have been mainly explained as follows: in general, while exercising, PAH subjects exhibit a limited increase in stroke volume, ${ }^{23,24}$ and the increase in $\mathrm{CO}$ is mainly achieved through increases in heart rate. However, chronic overactivity of the sympathetic nervous system leads to downregulation of $\beta$-adrenoceptors in the heart, ${ }^{25}$ which results in a small, slow heart-rate change during exercise in subjects with PAH. Although the physiology of chronic thromboembolic pulmonary hypertension is different from that of PAH (eg, mismatch of ventilation-perfusion, effect of pulmonary dilator), mechanisms similar to those in pulmonary hypertension can be considered in patients with chronic thromboembolic pulmonary hypertension. In patients with chronic thromboembolic pulmonary hypertension, right ventricular afterload increases during exercise, 


\section{MWT and Chronic Thromboembolic PAH}

and progression of the disease state eventually causes an impairment in right ventricular function due to chronic obstructions in pulmonary circulation. ${ }^{26}$ Because the impairment in right ventricular function causes a limited increase in stroke volume during exercise, the heart rate compensates for the demand for increased CO. Our results indicate small and slow heart-rate changes during exercise in subjects with severe chronic thromboembolic pulmonary hypertension. This finding suggests that this limited heart-rate response impairs exercise capacity, possibly suggesting that chronic overactivity of the sympathetic nervous system leads to downregulation of $\beta$-adrenoceptors in the heart of chronic thromboembolic pulmonary hypertension patients as well as those with PAH. Because we did not measure circulating catecholamine, we could not draw conclusions regarding these mechanisms in this study. However, a previous study of cardiac I-MIBG uptake indicated left ventricular sympathetic nervous dysfunction in subjects with pulmonary hypertension, including chronic thromboembolic pulmonary hypertension, ${ }^{27}$ which may support this speculation.

Regarding $\mathrm{S}_{\mathrm{pO}_{2}}$ during the $6 \mathrm{MWT}, \mathrm{S}_{\mathrm{pO}_{2}}$ reduction and recovery time were slower in subjects with severe chronic thromboembolic pulmonary hypertension than in those with mild chronic thromboembolic pulmonary hypertension. However, these parameters were not independently associated with pulmonary hemodynamics. Recovery time of $\mathrm{S}_{\mathrm{pO}_{2}}$ associated not only mean pulmonary arterial pressure but also $\mathrm{D}_{\mathrm{LCO}} / \mathrm{V}_{\mathrm{A}}$, while $\mathrm{S}_{\mathrm{pO}_{2}}$ reduction time associated $\mathrm{CO}$ and LVEF in subjects with chronic thromboembolic pulmonary hypertension. These results suggest that parameters of the change in $\mathrm{S}_{\mathrm{pO}_{2}}$ during the 6MWT do not directly reflect hemodynamics. This may be explained at least in part by the complexity of the mechanism of oxygen desaturation during exercise, which has been known to include gas-exchange abnormalities due to an increased dead-space ventilation ratio, a ventilation/perfusion mismatch, and insufficient $\mathrm{CO}$ due to right ventricular dysfunction. ${ }^{21,28-30}$

We have also demonstrated a change in 6MWT parameters both pre- and post-PEA. We originally hypothesized that the heart rate acceleration time would be reduced and the slope of heart rate acceleration would become steep due to improvements in pulmonary hemodynamics after PEA. However, improvement in the 6MWD in this study was only observed among 6MWT parameters, with the exception of 1 subject. Although the explanation for this is unclear, several possible factors can be considered, including reduction of pulmonary hypertension target agents and oxygen due to improved pulmonary hemodynamics, persistence of reduced right ventricular ejection fraction function after PEA,,$^{31,32}$ and small sample size. This issue requires further investigation.
An advantage of our study is that additional components of the 6MWT (ie, heart rate and $\mathrm{S}_{\mathrm{pO}_{2}}$ change patterns), which can be easily assessed by clinicians, may have the potential to reveal more precise physiological states of chronic thromboembolic pulmonary hypertension, although right heart catheterization is the gold standard to assess pulmonary hemodynamics in the clinical setting. ${ }^{1,3,33}$ Echocardiography is also widely used as an initial test for detecting pulmonary hypertension. ${ }^{13}$ However, the 6MWT is a noninvasive, simple, and inexpensive test that could be repeatedly performed anywhere. Collectively, these results indicate that evaluating heart rate and $\mathrm{S}_{\mathrm{pO}_{2}}$ change patterns during the 6MWT is potentially useful for patients with chronic thromboembolic pulmonary hypertension.

\section{Limitations}

Our study had the following limitations. This was a single-center retrospective study with a small number of subjects. There are 3 reasons for the small number of subjects: the study required several examinations (eg, right heart catheterization, pulmonary function test, 6MWT, and echocardiography); there were measurement errors in continuous monitoring pulse rate and $\mathrm{S}_{\mathrm{pO}_{2}}$ during the 6MWT (Fig. 1); and patients with chronic thromboembolic pulmonary hypertension are relatively rare. Future multi-center studies with larger cohorts of subjects are needed to confirm our results. Another limitation is that we could not conclude the effect of PEA for heart rate and $\mathrm{S}_{\mathrm{pO}_{2}}$ change patterns due to multiple confounding factors after the surgery (eg, reduction of pulmonary hypertension target agents and oxygen due to improvement in pulmonary hemodynamics, persistent pulmonary hypertension). In addition, our cohort included many females ( 27 females vs 4 males in 31 analyzed subjects; 45 females vs 9 males in original 54 patients; see Fig. 1), because chronic thromboembolic pulmonary hypertension is more common in women. However, the results of 4 males ( 3 mild, 1 severe disease state) show similarities with those of only male subjects (data are not shown). Finally, our study was unable to evaluate the relationship between heart rate patterns during the 6MWT and prognosis, including clinical worsening and mortality. Collectively, further investigation is required.

\section{Conclusions}

The change patterns of heart rate and $\mathrm{S}_{\mathrm{pO}_{2}}$ during the $6 \mathrm{MWT}$ are predominantly associated with pulmonary hemodynamics in subjects with chronic thromboembolic pulmonary hypertension. Therefore, in addition to the 6MWD, evaluating heart rate and $\mathrm{S}_{\mathrm{pO}_{2}}$ patterns during the 6MWT might provide a useful, safe, and convenient way to follow the change in pulmonary hemodynamics. 


\section{MWT and Chronic Thromboembolic PAH}

\section{ACKNOWLEDGMENTS}

We acknowledge Dr Akira Naito, Dr Hajime Kasai, Dr Toshihiko Sugiura, and Dr Rika Suda of the Department of Respirology, Graduate School of Medicine, Chiba University, and Ryogo Ema of the Department of Respirology, Eastern Chiba Medical Center, for their helpful comments.

\section{REFERENCES}

1. Galie N, Humbert M, Vachiery JL, Gibbs S, Lang I, Torbicki A, et al. 2015 ESC/ERS Guidelines for the diagnosis and treatment of pulmonary hypertension: The Joint Task Force for the Diagnosis and Treatment of Pulmonary Hypertension of the European Society of Cardiology (ESC) and the European Respiratory Society (ERS): Endorsed by: Association for European Paediatric and Congenital Cardiology (AEPC), International Society for Heart and Lung Transplantation (ISHLT). Eur Heart J 2016;37(1):67-119.

2. Riedel M, Stanek V, Widimsky J, Prerovsky I. Long-term follow-up of patients with pulmonary thromboembolism. Late prognosis and evolution of hemodynamic and respiratory data. Chest 1982;81(2): 151-158.

3. Tanabe N, Sugiura T, Tatsumi K. Recent progress in the diagnosis and management of chronic thromboembolic pulmonary hypertension. Respir Investig 2013;51(3):134-146.

4. ATS Committee on Proficiency Standards for Clinical Pulmonary Function Laboratories. ATS statement: guidelines for the six-minute walk test. Am J Respir Crit Care Med 2002;166(1):111-117.

5. Reesink HJ, van der Plas MN, Verhey NE, van Steenwijk RP, Kloek JJ, Bresser P. Six-minute walk distance as parameter of functional outcome after pulmonary endarterectomy for chronic thromboembolic pulmonary hypertension. J Thorac Cardiov Sur 2007;133(2): 510-516.

6. Saouti N, de Man F, Westerhof N, Boonstra A, Twisk J, Postmus PE, et al. Predictors of mortality in inoperable chronic thromboembolic pulmonary hypertension. Respir med 2009;103(7):1013-1019.

7. Jais X, D'Armini AM, Jansa P, Torbicki A, Delcroix M, Ghofrani HA, et al. Bosentan for treatment of inoperable chronic thromboembolic pulmonary hypertension: BENEFiT (Bosentan Effects in iNopErable Forms of chronIc Thromboembolic pulmonary hypertension), a randomized, placebo-controlled trial. J Am Coll Cardiol 2008;52(25):2127-2134.

8. Swigris JJ, Swick J, Wamboldt FS, Sprunger D, du Bois R, Fischer A, et al. Heart rate recovery after 6-min walk test predicts survival in patients with idiopathic pulmonary fibrosis. Chest 2009;136(3):841848.

9. Minai OA, Gudavalli R, Mummadi S, Liu X, McCarthy K, Dweik RA. Heart rate recovery predicts clinical worsening in patients with pulmonary arterial hypertension. Am J Respir Crit Care Med 2012; 185(4):400-408.

10. Provencher S, Chemla D, Herve P, Sitbon O, Humbert M, Simonneau G. Heart rate responses during the 6-minute walk test in pulmonary arterial hypertension. Eur Respir J 2006;27(1):114-120.

11. Chuang ML, Lin IF, Chen SP. Kinetics of changes in oxyhemoglobin saturation during walking and cycling tests in COPD. Respiratory care 2014;59(3):353-362.

12. Richter MJ, Milger K, Tello K, Stille P, Seeger W, Mayer E, et al. Heart rate response during 6-minute walking testing predicts outcome in operable chronic thromboembolic pulmonary hypertension. BMC Pulm Med 2016;16(1):96.

13. Kasai H, Matsumura A, Sugiura T, Shigeta A, Tanabe N, Ema R, et al. Noninvasive assessment of pulmonary vascular resistance by echocardiography in chronic thromboembolic pulmonary hypertension. Respir investig 2015;53(5):210-216.
14. Standardization of Spirometry, 1994 Update. American Thoracic Society. Am J Respir Crit Care Med 1995;152(3):1107-1136.

15. Borg GA. Psychophysical bases of perceived exertion. Med Sci Sport Exer 1982;14(5):377-381.

16. Taichman DB, McGoon MD, Harhay MO, Archer-Chicko C, Sager JS, Murugappan M, et al. Wide variation in clinicians' assessment of New York Heart Association/World Health Organization functional class in patients with pulmonary arterial hypertension. Mayo Clin Proc 2009;84(7):586-592.

17. Tonelli AR, Wang XF, Alkukhun L, Zhang Q, Dweik RA, Minai OA. Heart rate slopes during 6-min walk test in pulmonary arterial hypertension, other lung diseases, and healthy controls. Physiol Rep 2014;2(6):e12038.

18. Ramos RP, Arakaki JS, Barbosa P, Treptow E, Valois FM, Ferreira $\mathrm{EV}$, et al. Heart rate recovery in pulmonary arterial hypertension: relationship with exercise capacity and prognosis. Am Heart J 2012; 163(4):580-588.

19. Ciarka A, Doan V, Velez-Roa S, Naeije R, van de Borne P. Prognostic significance of sympathetic nervous system activation in pulmonary arterial hypertension. Am J Respir Crit Care Med 2010; 181(11):1269-1275.

20. Dimopoulos S, Anastasiou-Nana M, Katsaros F, Papazachou O, Tzanis G, Gerovasili V, et al. Impairment of autonomic nervous system activity in patients with pulmonary arterial hypertension: a case control study. J Card Fail 2009;15(10):882-889.

21. Sun XG, Hansen JE, Oudiz RJ, Wasserman K. Exercise pathophysiology in patients with primary pulmonary hypertension. Circulation 2001;104(4):429-435.

22. Riley MS, Porszasz J, Engelen MP, Brundage BH, Wasserman K. Gas exchange responses to continuous incremental cycle ergometry exercise in primary pulmonary hypertension in humans. Eur J Appl Physiol 2000;83(1):63-70.

23. Nootens M, Wolfkiel CJ, Chomka EV, Rich S. Understanding right and left ventricular systolic function and interactions at rest and with exercise in primary pulmonary hypertension. Am J Cardiol 1995; 75(5):374-377.

24. Laskey WK, Ferrari VA, Palevsky HI, Kussmaul WG. Pulmonary artery hemodynamics in primary pulmonary hypertension. J Am Coll Cardiol 1993;21(2):406-412.

25. Bristow MR, Minobe W, Rasmussen R, Larrabee P, Skerl L, Klein $\mathrm{JW}$, et al. Beta-adrenergic neuroeffector abnormalities in the failing human heart are produced by local rather than systemic mechanisms. J Clin Invest 1992;89(3):803-815.

26. Gerges C, Skoro-Sajer N, Lang IM. Right ventricle in acute and chronic pulmonary embolism (2013 Grover Conference series). Pulm Circ 2014;4(3):378-386.

27. Sakamaki F, Satoh T, Nagaya N, Kyotani S, Oya H, Nakanishi N, et al. Correlation between severity of pulmonary arterial hypertension and 123I-metaiodobenzylguanidine left ventricular imaging. J Nucl Med 2000;41(7):1127-1133.

28. Scheidl SJ, Englisch C, Kovacs G, Reichenberger F, Schulz R, Breithecker A, et al. Diagnosis of CTEPH versus IPAH using capillary to end-tidal carbon dioxide gradients. Eur Respir J 2012; 39(1):119-124.

29. McCabe C, Deboeck G, Harvey I, Ross RM, Gopalan D, Screaton N, et al. Inefficient exercise gas exchange identifies pulmonary hypertension in chronic thromboembolic obstruction following pulmonary embolism. Thromb Res 2013;132(6):659-665.

30. Zhai Z, Murphy K, Tighe H, Wang C, Wilkins MR, Gibbs JSR, et al. Differences in ventilatory inefficiency between pulmonary arterial hypertension and chronic thromboembolic pulmonary hypertension. Chest 2011;140(5):1284-1291.

31. Reesink HJ, Marcus JT, Tulevski II, Jamieson S, Kloek JJ, Vonk Noordegraaf A, et al. Reverse right ventricular remodeling after 


\section{MWT and Chronic Thromboembolic PAH}

pulmonary endarterectomy in patients with chronic thromboembolic pulmonary hypertension: utility of magnetic resonance imaging to demonstrate restoration of the right ventricle. J Thorac Cardiovasc Surg 2007;133(1):58-64.

32. Surie S, Bouma BJ, Bruin-Bon RA, Hardziyenka M, Kloek JJ, Van der Plas MN, et al. Time course of restoration of systolic and dia- stolic right ventricular function after pulmonary endarterectomy for chronic thromboembolic pulmonary hypertension. Am Heart J 2011; 161(6):1046-1052.

33. Kim NH, Delcroix M, Jenkins DP, Channick R, Dartevelle P, Jansa $\mathrm{P}$, et al. Chronic thromboembolic pulmonary hypertension. J Am Coll Cardiol 2013;62(25 Suppl):D92-D99. 